\title{
Research of Microstructure and Performance of Laser Cladding Fe-based Medium Manganese Alloy
}

\author{
CAI Zhihai ${ }^{1, a}$, ZHANG Ping ${ }^{1, b}$, Liang Xiubing ${ }^{1, c}$, Tantai Fanliang ${ }^{2, d}$, Yang \\ $\mathrm{Fan}^{2, \mathrm{e}}$
}

${ }^{1}$ National Engineering Research Center for Mechanical Product Remanufacturing, Academy of Armored Forces Engineering, BeiJing 100072, China

${ }^{2}$ Beijing Ronglu mechanical product remanufacturing technology Co. Ltd., Beijing 1000XX, China

1,a email: caizhihai2052@163.com,1,b zhangp5801@sina.com, 1,c email:liuxb2012@163.com,

2,demail:tantai@163.com, ${ }^{2, e}$ email:yangfan@163.com

Keywords: Fe-based medium manganese alloy; Laser cladding; Microstructure and performance; Tribological properties

\begin{abstract}
Fe-based medium manganese alloy coating was fabricated on 42CrMo steel surfaces using a synchronization powder feeding technique by $6 \mathrm{~kW}$ IPG laser apparatus. The microstructure and mechanical property were analyzed by X-ray diffractometer (XRD), scanning electron microscope (SEM), microhardness tester and SRV4 system. The results showed that the coating is divided into three parts: coating, bonding and HAZ. The microstructures are planar crystal, dendrite crystal, cellular crystal from bottom of the cladding to the top. The microhardness of the cladding layer is up to $739 \mathrm{HV}$, while that of the substrate is only $251 \mathrm{HV}$, the hardness incresses significantly. The abrasion performance of the cladding layer significantly improved, its relative wear resistance is 2.57 times of the substrate. After abrasion, the content of martensite in the cladding layer increases slightly, while the hardness increases.
\end{abstract}

\section{Introduction}

In medium and low impact load, the medium manganese alloy surface will have strain to induce martensitic transformation. The self enhancement feature makes it have good wear resistance and contact fatigue performance when be used. So it is widely used in mining machine, railway industry, armored vehicle caterpillar track, etc[1,2].

Add cladding material in the substrate surface, then use of high energy laser beam to fused With the substrate surface together, and form the metallurgical combination of cladding layer on the surface of the substrate, significantly change the wear-resisting, corrosion resistance, heat resistance, oxidation resistance and other properties of the substrate surface. Using laser cladding technology on the surface of the base material that cheap, easy to processing or damage parts selectively cladding on the surface of the special coating, to improve the surface performance or repair purposes[3,4]. This paper verifies the ferromanganese on 42CrMo steel cladding the Fe-based medium manganese alloy to improve the surface wear resistance. Meanwhile, the microstructure and the properties of cladding layer were studied.

\section{Materials and methods}

\subsection{Materials}

Experiment chooses $42 \mathrm{CrMo}$ steel as substrate material, its size is $70 \times 50 \times 30 \mathrm{~mm}$. $42 \mathrm{CrMo}$ steel is medium carbon alloy steel. It has excellent mechanical properties and process performance, and widely used in overload condition of gear, connecting rod, front axle and other parts. Its main components as shown in table 1. 
Table 1 Main components of 42CrMo steel (wt/\%)

\begin{tabular}{cccccc}
\hline $\mathrm{C}$ & $\mathrm{Si}$ & $\mathrm{Mn}$ & $\mathrm{Cr}$ & $\mathrm{Mo}$ & $\mathrm{Fe}$ \\
\hline 0.4 & 0.2 & $0.5 \sim$ & $0.9 \sim$ & $0.15 \sim$ & $\mathrm{B}$ \\
5 & 5 & 0.8 & 1.2 & 0.25 & $\mathrm{al}$ \\
\hline
\end{tabular}

The Fe-based medium manganese alloy powder uesd in cladding was production by adding the solvent in the tank waste segments and through Aerosol polarization method. The particle size is $-120 \sim+300$, to ensure that it has good liquidity and helpful to form good cladding layer surface. Its main components as shown in table 2.

Table 2 Main components of Fe-based medium manganese alloy powder (wt/\%)

\begin{tabular}{cccccc}
\hline $\mathrm{C}$ & $\mathrm{Mn}$ & $\mathrm{Mo}$ & $\mathrm{Cr}$ & $\mathrm{B}$ & $\mathrm{Fe}$ \\
\hline $0.9 \sim$ & $8.5 \sim$ & $1.5 \sim$ & $1 \sim$ & $0.1 \sim$ & $\mathrm{B}$ \\
1.0 & 9.0 & 2 & 1.2 & 0.3 & $\mathrm{al}$ \\
\hline
\end{tabular}

\subsection{Test equipment}

2.2.1 .Laser cladding platform

Using 6kw IPG fiber laser, connect to KUKA KR30HA robot by the optical fiber with a diameter of 200 microns, as a platform of laser cladding. Laser power is $1.8 \mathrm{~kW}$, spot diameter is $3 \mathrm{~mm}$. Using a synchronization powder feeding technique by the lateral powder. Ar feeding powders with the rate of $8.0 \mathrm{~g} / \mathrm{min}$. Laser scanning speed is $5 \mathrm{~mm} / \mathrm{s}$.

\subsubsection{Structure and composition}

Take the cross section of cladding layer to prepare metallographic specimen. After corrosion by 3\% nitric acid alcohol solution, using OM and SEM to observe the structure of coating, and using XRD for phase analysis.

\subsection{3 .Microhardness}

The microhardness is measured by multifunctional surface performance measuring instrument of Buehler Ltd. of USA, with Load $0.98 \mathrm{~N}$ and loading time $15 \mathrm{~s}$.

\subsection{4 .Frictional characteristic}

Using the SRV - 4 micro friction and wear testing machine of German Optimol Instruments test the cladding layer friction resistance. Experiment at room temperature, without lubrication conditions, load $50 \mathrm{~N}, 10 \mathrm{~Hz}$ frequency, friction stroke $2 \mathrm{~mm}$, friction time $30 \mathrm{~min}$, friction pair using $\mathrm{Si} 3 \mathrm{~N} 4$ ceramic ball, with $10 \mathrm{~mm}$ in diameter and the hardness is $1800 \mathrm{HV}$. Respectively test friction of the substrate and the Fe-based medium manganese alloy coating, the wear volume is measured by $3 \mathrm{~d}$ profilometer. And the coating friction sample is double cladding with $50 \%$ lap rate.

\subsection{Test method}

In order to reduce the tendency to cracking, the powder is dried $2 \mathrm{~h}$ in $120^{\circ} \mathrm{C}$ before cladding to remove moisture. Sanding substrate surface with 400 mesh sandpaper and cleaning with acetone, to remove the oil and rust stains.

\section{Results and analysis}

\section{1 .Organizational characteristics of coating}

The Fe-based medium manganese alloy coating in the surface of flat light, and no defects such as blowholes, cracks. Using optical microscopy, cladding layer thickness $1 \mathrm{~mm}$, the width $3 \mathrm{~mm}$, as shown in figure 1 . Between the coating and heat affected zone has a $5 \mu \mathrm{m}$ wide "white band", this is a layer of crystal plane. The emergence of "white band" prove that between the coating and substrate formed a good metallurgical combination. 


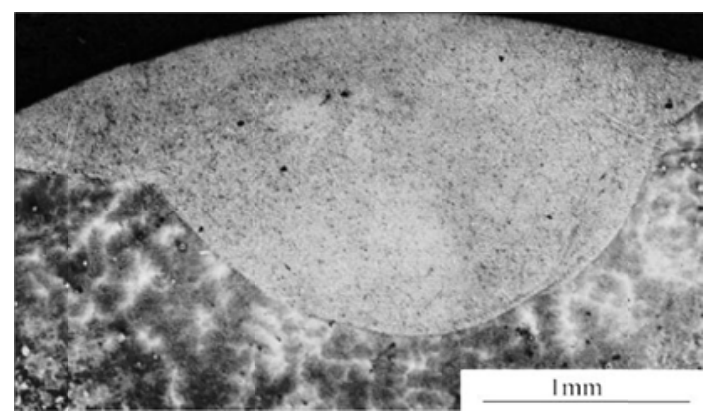

Fig.1 Cross section of Fe-based medium manganese alloy coating

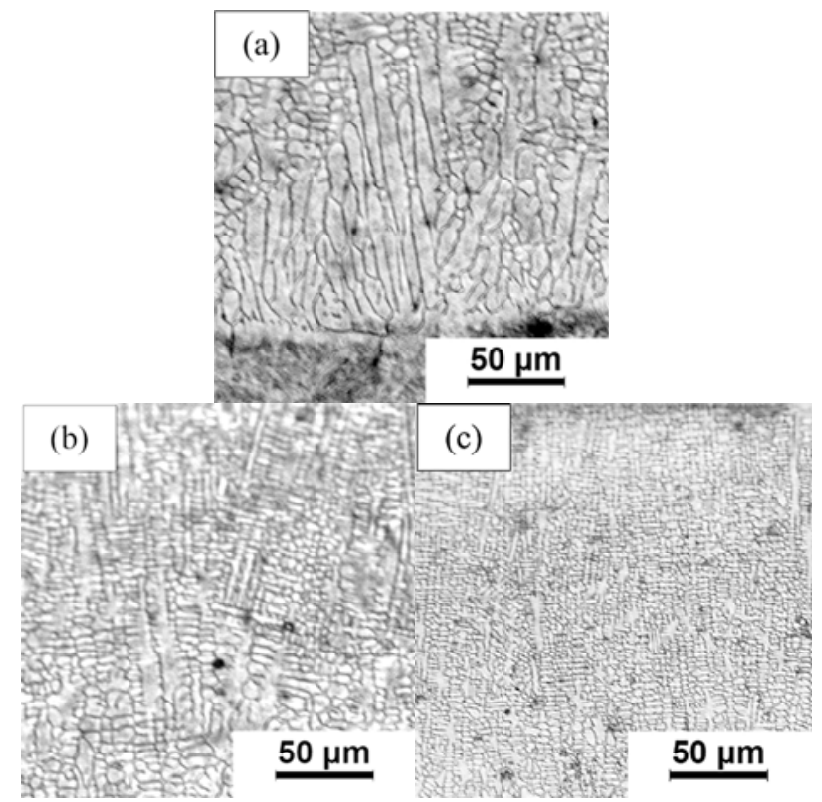

Fig.2 Structure morphology of coating(a) bottom (b) middle $\quad$ (c) top

Figure 2 is the Structure morphology of coating, (a) to the bottom of the coating, (b) as the central, (c) for the top, from the bottom to the top, the structure followed by columnar crystal, dendrites, isometric. The structure morphologies of the coating is decided by the temperature gradient/solidification rate $(\mathrm{G} / \mathrm{R})$. Due to the dynamic changes of the cladding molten pool, the time of solidification condition is great differences, lead to the different structure. At the interface of the bottom of coating, the initial solidification rate close to zero, but the maximum temperature gradient, $\mathrm{G} / \mathrm{R}$ is huge, So at the bottom, the structure form of crystal plane, namely the "white band" in figure 1. As solidification, $R$ decreases, $G$ increases gradually, $G / R$ is less also, structure form to make the transition to dendrites, isometric[5,6].

The structure of the medium manganese steel at room temperature is austenitic, and martensitic transformation will happen under the action of impact load. Figure 3 is the Fe-based medium manganese alloy coating in the X-ray diffraction pattern. It can be seen that the structure is composed of austenite, martensite and carbide, and austenite in the majority. 


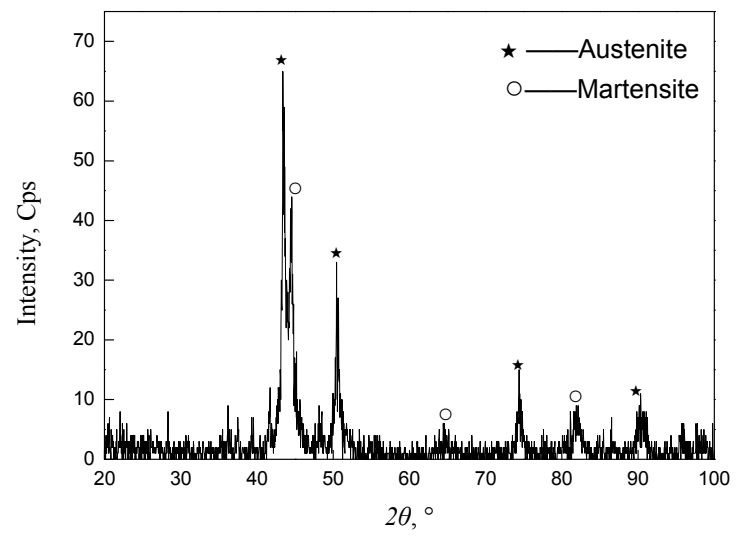

Fig.3 The X-ray diffraction pattern of the Fe-based medium manganese alloy coating

\subsection{Hardness of the Coating}

Measured the hardness of the coating every $200 \mu \mathrm{m}$ from the top to the bottom, at every depth test at least three points to obtain the average hardness. The hardness distribution curve of the coating is shown in Figure 4. From the figure, we can find that from the coating to the substrate, the hardness decreased stepwise. The hardness of the coating is above 700HV0.05, the maximum hardness is up to $739 \mathrm{HV} 0.05$. And with the increasing distance from the surface, the hardness decreases slightly. due to the impact of the thermal cycles, martensite was formed in the the HAZ, the hardness increased to 550HV0.05-600HV0.05. The hardness of the substrate is around $250 \mathrm{HV} 0.05$, while the hardness of the coating is nearly three times of the substrate.

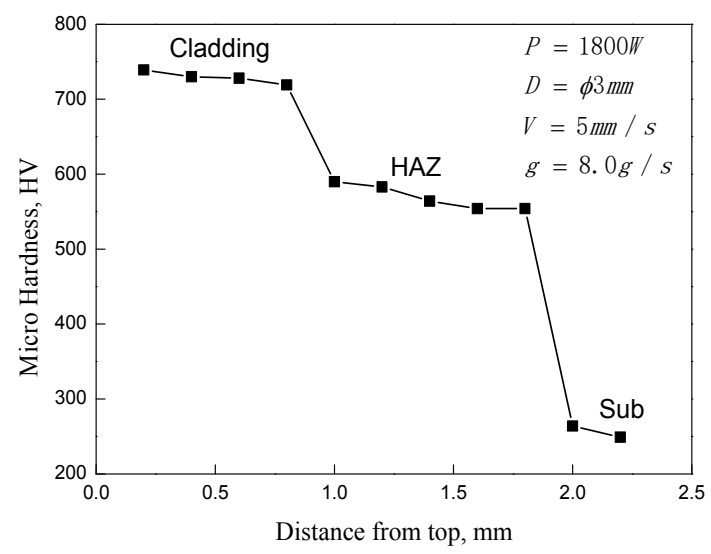

Fig. 4 coating microhardness curve

\subsection{Friction properties of the coating}

Examine the friction properties of the substrate and the coating with SRV4. The wear volume of the substrate and the coating are tested with $3 \mathrm{D}$ profilometer. The result is shown in figure 5 . The wear resistance of the coating is much better than that of substrate under the same condition. The relative wear resistance of the coating is 2.57 times that of the substrate. 


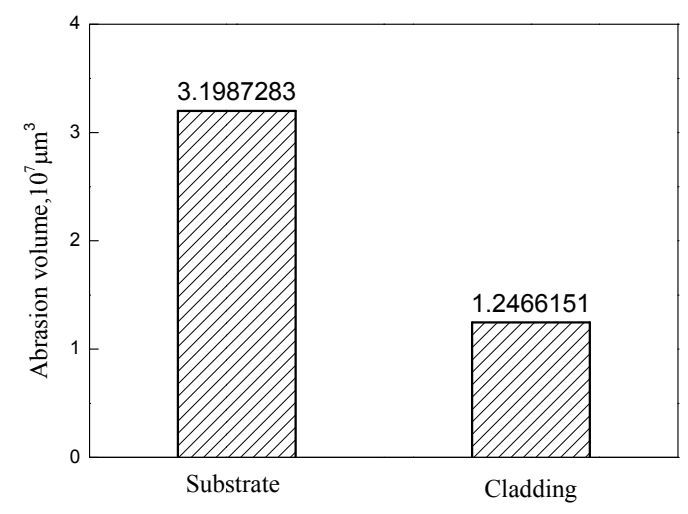

Fig. 5 Wear volume of the substrate and coating

\subsection{Comparison of structure and hardness before and after the friction}

The structure of the coating after the friction was characterized by XRD, and the relative content of martensite and austenite was determined by the method of fixed ' $\psi$ '. Micro hardness tester was used to measure the hardness of coating before and after the friction. The result is shown in figure 6 . The content of martensite in the coating after friction increased from $39.4 \%$ to $43.1 \%$, and microhardness increased from 641.1 HV0.05 to 697.7 HV0.05.

Hardness increased after the friction because of medium manganese steel has the characteristics of transform to martensite phase in the impact load. When friction, under the effect of load, part austenite of the coating transformed to martensite phase, so the hardness increases.

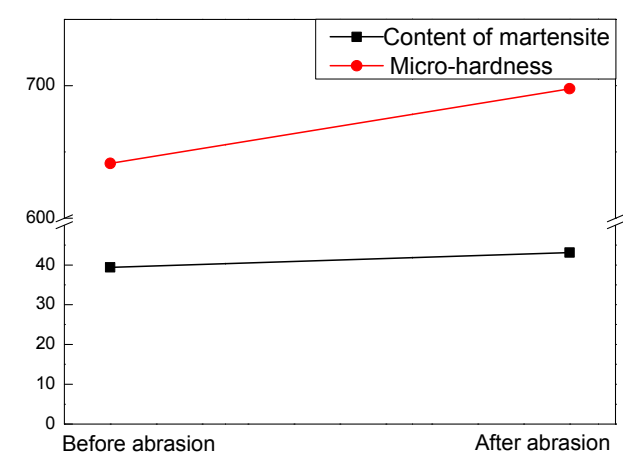

Fig. 6 Comparison of austenite content and microhardness before and after comparison

\subsection{Friction and Wear Mechanism}
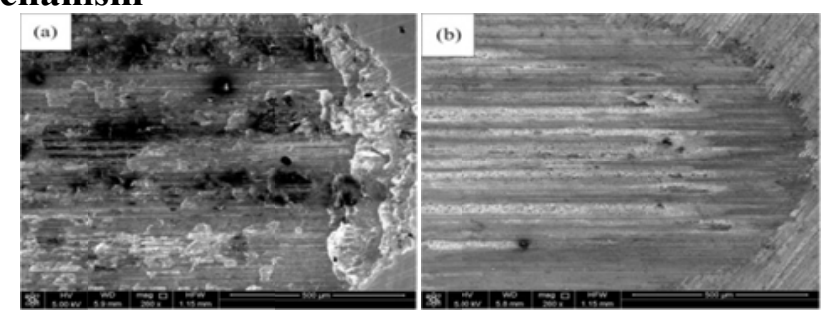

Fig. 7 Worn-out Appearance（a）42CrMo Substrate（b ） Coating

The grinding crack of substrate and Fe-based medium manganese alloy coating was observed with SEM. As shown in figure 7, (a) is the 42CrMo substrate, (b) is coating. As can be seen from the grinding crack morphology, the wear form of $42 \mathrm{CrMo}$ substrate is mainly peeling wear. Under the effect of cyclic loading, the fatigue occurred on the material sub-surface where internal stress concentrated. Then the initiation crack extended bifurcately to the material surface. The layer exfoliated causes loss of material. The wear forms of Fe-based medium manganese alloy coating are mainly abrasive wear. Fallen Hard particles from the friction pair or convex body embedded into 
surface under the effect of pressure. With the movement of friction pair, the material plastically deformed, the furrows formed. Different form of friction lead to different wear resistance.

\section{Conclusions}

(1) Fe-based medium manganese alloy coating was prepared on 42CrMo substrate by laser cladding. The structure of the coating is columnar crystals, dendrites, equiaxed from bottom to top. The phases of the coating are austenite and martensite. The hardness of the coating is above $700 \mathrm{HV} 0.05$, the maximum hardness is up to $739 \mathrm{HV}$, which is about three times of the substrate.

(2) Wear resistance of the ferromanganese coating is much better than 42CrMo substrate. The relative wear volume of the ferromanganese coating is 2.57 times of the substrate under the same conditions. The wear forms of Fe-based medium manganese alloy coating are mainly abrasive wear, while the wear form of $42 \mathrm{CrMo}$ substrate is mainly peeling wear.

\section{Acknowledgement}

In this paper, the research work was sponsored by the Fund for Science and Technology Project of Beijing.

\section{References}

[1] Tian Haoliang, Liu Yunfeng, Zhang Ping, etc. Research and development of alloyed austenite medium manganese steel and its impact abrasive wear resistance[J].Heat treatment of metals. 2013,2(38):30-34.

[2] Yuan Jinping, Zhang Ping, Liang Zhijie, et al . Eff ect of Mo and $\mathrm{CeO} 2$ on microstructure and properties of laser cladding nickel base alloy coatings $[\mathrm{J}]$. Rare Met al Mat erials and Engineering, 2008, 37(1) : 147- 151.

[3] Zhu Bailin, Hu Mul in, Chen Li, et al . Research status of cracking in laser cladding layer [ J] . Metals and Heat Treatment, 2000( 7) : 1- 4.

[4] Shin Jong Chou,1 Doh Jung Man, Yoon Jin Kook, et a.l Effect of Molybdenum on the M icrostructure and Wear Res istance of Cobalt base Stel lite Hardfacing Alloys[ J] . Surface and Coatings Technology, 2003, 166: 117- 126.

[4] DING Yangxi, WU Jilin. Influence of laser cladding parameters on microstructure and properties of cladding layer[J]. Hot Working Technology. 2010,39(2):94-96.

[5] WU Xiaolei, Chen Guangnan. Microstructrual characterization and evolution of laser clad Fe-based alloys[J]. Acta metallurgica sinica. 1998,34(10):1033-1038.

[6] Wu P, Zhou C Z, Tang X N. M icrostructu ral characterization and wear behavior of laser cladded nickel based and tungsten carbide composite coatings [J]. Surface and Coatings Technology, 2003, 166: 84- 88. 